\title{
Macronutrient content of plant-based food affects growth of a carnivorous arthropod
}

\author{
Shawn M. Wilder,${ }^{1,4}$ David A. Holway, ${ }^{2}$ Andrew V. Suarez, ${ }^{3}$ and Micky D. Eubanks ${ }^{1}$ \\ ${ }^{1}$ Department of Entomology, Texas A\&M University, College Station, Texas 77843 USA \\ ${ }^{2}$ Division of Biological Sciences, University of California at San Diego, La Jolla, California 92093 USA \\ ${ }^{3}$ Department of Entomology and Department of Animal Biology, University of Illinois at Urbana-Champaign, Urbana, Illinois 61801 USA
}

Abstract. Many arthropods engage in mutualisms in which they consume plant-based foods including nectar, extrafloral nectar, and honeydew. However, relatively little is known about the manner in which the specific macronutrients in these plant-based resources affect growth, especially for carnivorous arthropods. Using a combination of laboratory and field experiments, we tested (1) how plant-based foods, together with ad libitum insect prey, affect the growth of a carnivorous ant, Solenopsis invicta, and (2) which macronutrients in these resources (i.e., carbohydrates, amino acids, or both) contribute to higher colony growth. Access to honeydew increased the production of workers and brood in experimental colonies. This growth effect appeared to be due to carbohydrates alone as colonies provided with the carbohydrate component of artificial extrafloral nectar had greater worker and brood production compared to colonies deprived of carbohydrates. Surprisingly, amino acids only had a slight interactive effect on the proportion of a colony composed of brood and negatively affected worker survival. Diet choice in the laboratory and field matched performance in the laboratory with high recruitment to carbohydrate baits and only slight recruitment to amino acids. The strong, positive effects of carbohydrates on colony growth and the low cost of producing this macronutrient for plants and hemipterans may have aided the evolution of food-for-protection mutualisms and help explain why these interactions are so common in ants. In addition, greater access to plant-based resources in the introduced range of $S$. invicta may help to explain the high densities achieved by this species throughout the southeastern United States.

Key words: ant-hemipteran-plant mutualism; aphid honeydew; food for protection; Gossypium hirsutum; mutualisms; nectar; nutritional ecology; plant-based resources; red imported fire ant; Solenopsis invicta; Texas, USA.

\section{INTRODUCTION}

Mutualisms are widespread among plants and animals and can affect population and community dynamics (Bronstein 1994, Wäckers et al. 2005). Many mutualisms involve the transfer of resources (e.g., plant-based resources such as nectar, extrafloral nectar, and honeydew) in exchange for services (e.g., pollination or protection) (Bronstein 1998, Stadler and Dixon 2005, Wäckers et al. 2005). Resources provided by plants or hemipterans typically contain high concentrations of carbohydrates and low concentrations of amino acids (e.g., an average of $310 \mathrm{~g} / \mathrm{L}$ for carbohydrates and $3 \mathrm{~g} / \mathrm{L}$ for amino acids; Blüthgen et al. 2004). However, there can be over 100 -fold variation in the concentrations of carbohydrates (4-986 g/L) and amino acids (0.02-26.7 $\mathrm{g} / \mathrm{L}$ ) in plant-based resources (Blüthgen et al. 2004). A better understanding of how such variation affects the growth and survival of consumers will provide insight into the costs and benefits of participating in mutualistic

Manuscript received 25 March 2010; revised 7 June 2010; accepted 12 July 2010. Corresponding Editor: R. A. Raguso.

${ }^{4}$ E-mail: wilder.shawn@gmail.com interactions and, more generally, the conditions under which mutualisms are formed and maintained.

For some consumers, the motivation for consuming plant-based foods is clear. For example, in active animals such as hummingbirds and adult Lepidoptera, plantbased foods provide a key source of carbohydrates to fuel the high metabolic costs of flight (Hainsworth and Wolf 1972, Josens and Farina 1997). However, the importance of plant-based foods for the diet of other animals is less well understood. For example, the high carbohydrate and low amino acid content of plant-based foods seems inconsistent with the high nitrogen requirements hypothesized for carnivorous arthropods (White 1978, Fagan et al. 2002, Denno and Fagan 2003, Fagan and Denno 2004). Yet, carnivorous arthropods frequently engage in mutualisms with plants and Hemiptera that produce plant-based resources and consumption of these foods has positive effects on activity level, longevity, and growth (Eubanks 2005, Stadler and Dixon 2005, Wäckers et al. 2005, Helms and Vinson 2008). It is not known whether the effects of plant-based foods on the performance of carnivorous arthropods are due to the carbohydrates, amino acids, or both. Experimental tests of how the 
macronutrient content of plant-based resources affects carnivore performance may reveal whether the low amino acid content provides more of a benefit than would be expected based on its concentration or whether carbohydrates are an underappreciated macronutrient for growth of carnivorous arthropods. In addition, the effects of carbohydrates and amino acids on carnivore performance may provide insight into the likelihood with which individuals should engage in mutualisms with plants or hemipterans that provide different concentrations of these macronutrients.

Consumption of plant-based foods may also be important for the establishment and spread of invasive arthropods. Some invasive ants may have greater access to plant-based resources in their introduced range than in their native range (Tillberg et al. 2007). In the southeastern United States, the red imported fire ant (Solenopsis invicta) is responsible for significant ecological, health, and economic impacts (Tschinkel 2006). Solenopsis invicta is a carnivorous ant that primarily consumes animal tissue and haemolymph and has a $\delta^{15} \mathrm{~N}$ stable isotope signature similar to that of obligate predators, such as spiders (Tennant and Porter 1991, Vogt et al. 2002, Tillberg et al. 2007). However, S. invicta also frequently forms mutualisms with honeydew-producing hemipterans in their introduced range (Helms and Vinson 2002) and these interactions influence how $S$. invicta affects arthropod food webs (Kaplan and Eubanks 2005). In addition, consumption of honeydew increases colony growth rate of S. invicta, although the mechanisms responsible for this increase (e.g., greater worker longevity, higher rates of brood production, or both) remain unclear (Helms and Vinson 2008). Testing how the macronutrient content of plantbased resources affects carnivorous arthropods may provide a better understanding of the spread, ecological impacts, and control of invasive species such as $S$. invicta.

The purpose of this study was to examine the benefits of consuming plant-based resources for a carnivorous insect, the red imported fire ant (Solenopsis invicta), and to test which nutritional components of plant-based resources (i.e., carbohydrates, amino acids, or both) contributed to higher colony growth. In the first part of this study, we quantified the effects of aphid honeydew on worker and brood production of $S$. invicta colonies reared in the laboratory. In the second part of this study, we separated the carbohydrate and amino acid components of artificial extrafloral nectar to test: (1) which macronutrients contributed to colony growth in the laboratory and (2) which were preferentially collected by colonies in the laboratory and field.

\section{Methods}

\section{General methods for laboratory experiments}

Colonies of polygyne $S$. invicta were excavated from the campus of Texas A\&M University (College Station, Brazos County, Texas, USA) in the spring of 2008 and
2009. After 48 hours, water was used to separate workers, brood, and queens from the soil. This material was used to make standardized laboratory colonies that each consisted of 1-20 queens (to test the effects of aphid honeydew on colony growth) or two queens (to test the effects of carbohydrates and amino acids on growth), $\sim 50$ brood and $1 \mathrm{~g}$ wet mass of workers $(0.345$ \pm 0.009 g dry mass or $1192 \pm 62$ individuals; mean \pm 1 $\mathrm{SE}$ ). Polygyne colonies in the field vary in the number of queens present (Tschinkel 2006). However, the number of queens had no effect on colony size in experiment 1 (general linear model ANOVA, number of workers, $F_{1,28}=0.26, P=0.61$; number of brood, $F_{1,28}=0.45, P=$ $0.51)$. For this reason, we used two queens in each colony for experiment 2. Each colony from the field was used to make a single laboratory replicate. Laboratory colonies were housed in containers $(56 \mathrm{~cm}$ length $\times 40$ $\mathrm{cm}$ width $\times 14 \mathrm{~cm}$ height) lined with fluon and provided with a darkened petri dish lined with plaster of paris for a nest. Colonies were provided with a vial of water and had the plaster of paris substrate moistened two times per week. Each colony was provided with two freshly killed crickets, Acheta domesticus, three times per week, which was ad libitum prey for colonies used in these experiments. The use of ad libitum insect prey is consistent with conditions in nature as colonies of $S$. invicta regularly dry and store pieces of insects in colony chambers in the field (Gayahan and Tschinkel 2008). The colony room was maintained on a 12:12 light: dark photoperiod with $40-70 \%$ humidity and a daily temperature cycle that included $8 \mathrm{~h}$ during daylight at $32^{\circ} \mathrm{C}$ and $16 \mathrm{~h}$ at $24^{\circ} \mathrm{C}$. Colonies were maintained in the laboratory for $45 \mathrm{~d}$ in experiment 1 and $60 \mathrm{~d}$ in experiment 2 after which they were frozen. We then separated workers and brood, dried them at $60^{\circ} \mathrm{C}$ for $48 \mathrm{~h}$, and weighed them.

\section{Effects of aphid honeydew on colony growth}

This laboratory experiment quantified the growth of colonies of $S$. invicta in the presence of high and low densities of aphids. Each container with fire ants received three cotton plants, Gossypium hirsutum, in $8.75 \mathrm{~cm}$ square plastic pots containing potting soil, in which $S$. invicta readily nested. The aphid treatment $(n=$ 15) was created by adding cotton aphids, Aphis gossypii, to plants and allowing populations to become established while the control treatment $(n=17)$ was maintained by searching cotton plants twice each week and killing any aphids found. Cotton plants had extrafloral nectaries. However, given the low number of extrafloral nectaries, nectar consumption by ants was likely low compared to the amount of honeydew consumed (Adjei-Maafo and Wilson 1983, Fischer et al. 2002). Cotton plants that grew too large for the plastic pots were replaced with smaller plants. Only one cotton plant was replaced at a time and the pot with the plant that was removed was allowed to dry for one week before it was removed so that all worker and brood would move out of that pot and into the other remaining 
pots. At 12,19 , and $26 \mathrm{~d}$ after the start of the experiment, we counted the number of aphids on each leaf of each plant. At the end of the experiment, we removed the soil from all of the pots and spread it in a thin layer on the bottom of the containers. We also added a petri dish that was painted black and included moistened cotton to each container. As the soil in the container dried, the ants moved into the petri dish with the brood. After $2 \mathrm{~d}$, we removed the petri dish, visually searched containers for any remaining ants, and placed all ants and brood in a freezer. Two-factor ANOVA was used to test for the effects of aphid treatment and the number of queens on the dry mass of workers and brood present in colonies after $45 \mathrm{~d}$ on the experimental treatments. A repeated-measures ANOVA was used to compare the mean number of aphids per leaf between plants in the aphid and control treatments for the three sampling dates.

\section{Effects of carbohydrates and amino acids on colony growth}

We conducted a second laboratory experiment to test the effects of the carbohydrate and amino acid components of artificial extrafloral nectar on colony growth of $S$. invicta. We randomly assigned colonies to four treatments that, in addition to insect prey, were supplemented with a 5 -mL vial of either: water $(n=12)$; a solution containing only the carbohydrate component of extrafloral nectar $(n=13)$; a solution containing only the amino acid component $(n=15)$; or a solution with both components $(n=14)$. Artificial nectar mimicked the chemical composition of extrafloral nectar of Passiflora spp. (Lanza 1991) and consisted of 1 L of water mixed with carbohydrates (108 g sucrose, $90 \mathrm{~g}$ glucose, $53 \mathrm{~g}$ fructose) and amino acids (0.0232 $\mathrm{g}$ aspartic acid, $0.512 \mathrm{~g}$ glutamine, $0.0404 \mathrm{~g}$ glutamic acid, $0.0194 \mathrm{~g}$ histidine, $0.0436 \mathrm{~g}$ isoleucine, $0.04 \mathrm{~g}$ leucine, $0.118 \mathrm{~g}$ phenylalanine, $0.368 \mathrm{~g}$ proline, $0.0704 \mathrm{~g}$ tryptophan, and $0.1122 \mathrm{~g}$ tyrosine). This artificial nectar recipe has carbohydrate $(251 \mathrm{~g} / \mathrm{L})$ and amino acid $(1.3 \mathrm{~g} / \mathrm{L})$ concentrations similar to a wide range of extrafloral nectars (carbohydrate, mean $=222$, median $=183$; amino acid, mean $=3.4$, median $=1$; Blüthgen et al. 2004). Plant-produced extrafloral nectar also contains a number of other compounds including volatiles, used in long-distance attraction, and antimicrobial chemicals (González-Teuber and Heil 2009). However, our artificial extrafloral nectar only included carbohydrates and amino acids because these are thought to be the major nutritional components that contribute to the survival and growth of consumers (Blüthgen et al. 2004, Stadler and Dixon 2005). Vials with experimental treatments were replaced twice each week.

Twenty-eight days after the laboratory colonies were established, we collected and counted the number of dead worker ants in each colony. Solenopsis invicta, like many other ants, places dead worker ants in one or more piles away from the nest (Hölldobler and Wilson 1990).
This behavior allowed us to record accurate counts of the number of dead ants without disturbing the colony. On three separate dates $(1,9$, and $16 \mathrm{~d}$ after the start of the experiment) we also counted the number of $S$. invicta collecting liquid from the experimental treatment vials. We counted the number of ants on the vials 60 min after a new treatment vial was added to the colony. The duration of larval growth and pupation is $\sim 30 \mathrm{~d}$ at $32^{\circ} \mathrm{C}$ in S. invicta (Tschinkel 2006). Hence, the collection of dead ants and data on feeding from treatment vials occurred before colonies had a chance to increase the number of workers present.

Two-factor ANOVAs were used to test for the effects of carbohydrates and amino acids on the dry mass of workers, dry mass of brood, number of dead workers, and proportion of the colony composed of brood at the end of the experiment. A two-factor, repeated-measures ANOVA was used to test for the effects of carbohydrates and amino acids on the number of ants collecting liquid from the experimental treatment vials.

\section{Diet choice in the field}

We conducted an experiment in the field to examine the preference of $S$. invicta colonies for solutions containing carbohydrates, amino acids, or both. One potential criticism of this approach is that carbohydrates and amino acids are present in very different concentrations and that diet selection could be dose dependent. Dose dependence can occur in studies of diet selection; however, it is always between solutions that have different concentrations of the same macronutrient (e.g., Josens and Farina 1997, Blüthgen and Fiedler 2004). When consumers are choosing between different macronutrients, consumers will select the macronutrient that is limiting and consume that macronutrient until their dietary requirement is fulfilled (e.g., Mayntz and Toft 2001, Mayntz et al. 2005, Raubenheimer et al. 2007).

To facilitate counting ants feeding on different solutions in the field, we combined the treatment solutions (water, carbohydrates only, amino acids only, or both the carbohydrate and amino acid component of extrafloral nectar) with agar to form a soft bait pellet (112 $\mathrm{mL}$ of solution with $0.8 \mathrm{~g}$ of agar). On two dates, we created transects of 15 bait stations spaced $10 \mathrm{~m}$ apart and placed one of each of the bait treatments at each station (i.e., a simultaneous choice test). Transects were placed in post oak savannah habitat at the field laboratory on the campus of Texas A\&M University in College Station, Texas, in June 2009. After 60 min, we returned to each bait and counted the number of $S$. invicta feeding on the bait. Two-factor ANOVA was used to test for the effects of carbohydrates and amino acids on the number of ants at the baits after $60 \mathrm{~min}$.

\section{RESUlts}

\section{Effects of aphid honeydew on colony growth}

We were successful at creating experimental treatments with different aphid density as plants in the aphid 


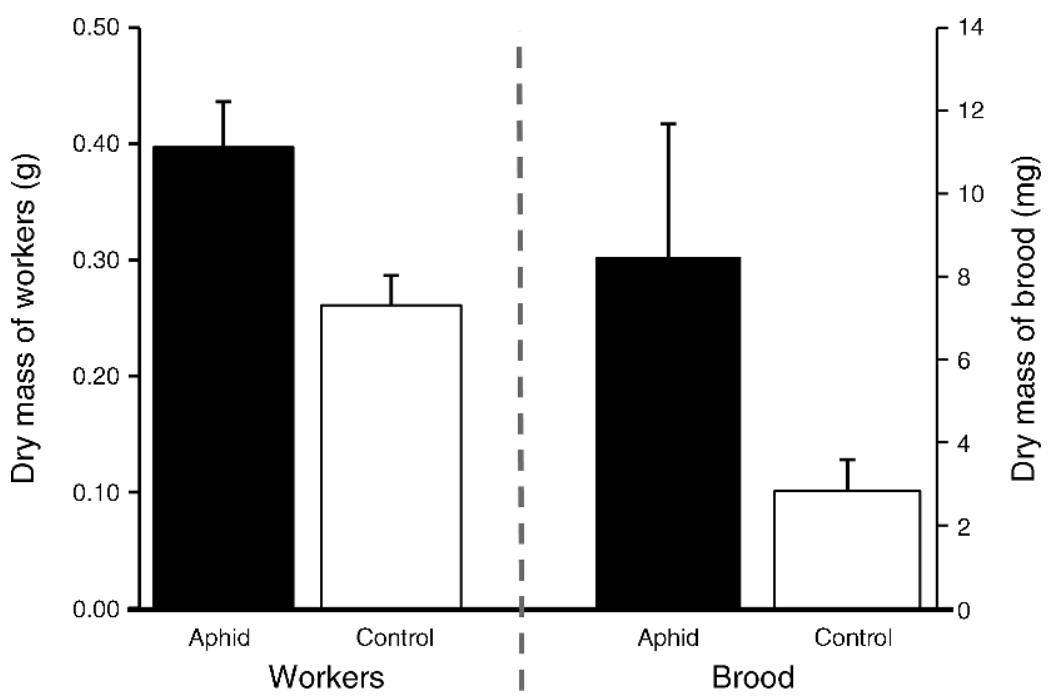

FIG. 1. Comparison of the final dry mass of workers and brood (mean $+\mathrm{SE}$ ) from colonies of the carnivorous red imported fire ant, Solenopsis invicta, provided access to honeydew from cotton aphids on cotton plants (Aphid) or just cotton plants (Control). Colonies of polygyne $S$. invicta were excavated from the campus of Texas A\&M University, College Station, Brazos County, Texas, USA.

treatment had over three times as many aphids on each leaf $(130.7 \pm 2.7$ aphids/leaf $)$ compared to plants in the control treatment $(43 \pm 1.5$ aphids/leaf) (repeatedmeasures ANOVA: treatment effect, $F_{1,15}=32.12, P<$ 0.001 ). After $45 \mathrm{~d}$, colonies of $S$. invicta in the aphid treatment had almost $50 \%$ higher dry mass of workers $\left(F_{1,28}=8.07, P=0.008\right)$ and $>200 \%$ higher dry mass of brood $\left(F_{1,28}=4.70, P=0.039\right)$ compared to control colonies (Fig. 1).

\section{Effects of carbohydrates and amino acids on colony growth}

Colonies with carbohydrate supplements had almost $100 \%$ higher dry mass of workers $\left(F_{1,33}=17.59, P=\right.$ 0.0002 ; Fig. 2A) and $>100 \%$ higher dry mass of brood $\left(F_{1,33}=9.77, P=0.004\right.$; Fig. 2 B) compared to colonies deprived of carbohydrates. There was no effect of amino acids and no interaction between carbohydrates and amino acids on the dry mass of workers (amino acids, $F_{1,33}=0.92, P=0.34$; interaction, $F_{1,33}=0.39, P=0.53$ ) or brood (amino acids, $F_{1,33}=0.47, P=0.50$; interaction, $\left.F_{1,33}=1.88, P=0.18\right)$ at the end of the experiment.

Colonies with supplemental carbohydrates had 54\% lower mortality ( $111 \pm 35$ workers dead) compared to colonies deprived of carbohydrates $(245 \pm 33$ workers dead; $\left.F_{1,27}=16.37, P=0.0004\right)$. However, the consumption of amino acids resulted in a $60 \%$ increase in mortality ( $219 \pm 35$ workers dead) relative to colonies that did not have amino acids $(137 \pm 33$ workers dead; $F_{1,27}=5.40, P=0.03$ ).

While there were no significant main effects of carbohydrates $\left(F_{1,33}=2.09, P=0.16\right)$ or amino acids $\left(F_{1,33}=0.03, P=0.86\right)$ on the proportion of a colony composed of brood, there was a significant interaction between these effects $\left(F_{1,33}=6.42, P=0.02\right.$; Fig. 3$)$. When no carbohydrates were present, the addition of amino acids resulted in a $57 \%$ reduction in the proportion of colony mass that was brood. However, when carbohydrates were present, the addition of amino
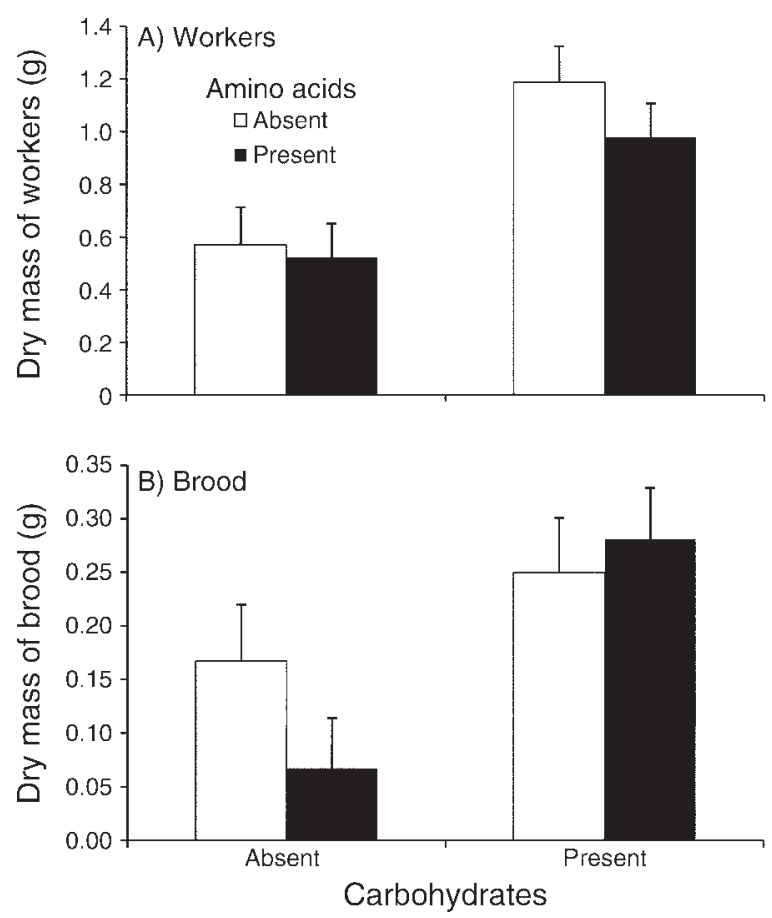

FIG. 2. Comparisons of the effects of a full factorial manipulation of the presence and absence of the carbohydrate and amino acids components of artificial extrafloral nectar on the final dry mass of (A) workers and (B) brood in colonies of Solenopsis invicta (mean $+\mathrm{SE})$. 


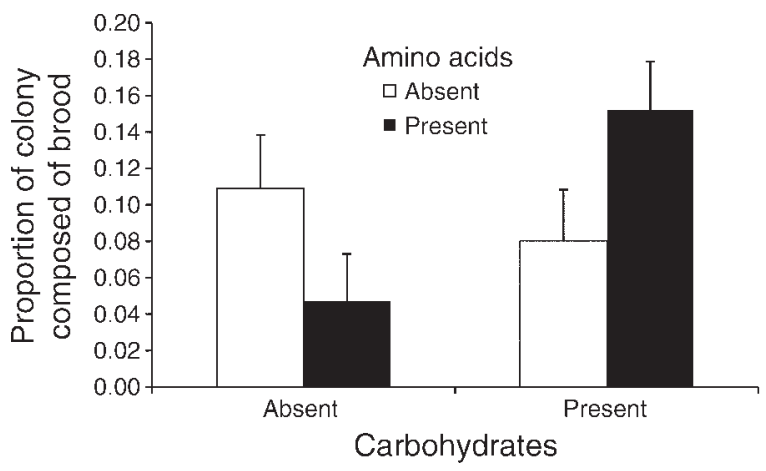

FIG. 3. Comparisons of the effects of a full factorial manipulation of the presence and absence of the carbohydrate and amino acids components of artificial extrafloral nectar on the proportion of a colony composed of brood (i.e., mass of brood/total colony mass; mean $+\mathrm{SE}$ ).

acids resulted in a $90 \%$ increase in the proportion of a colony that was brood (Fig. 3).

Workers of S. invicta recruited to vials with carbohydrates in much higher numbers than they did to vials that did not have carbohydrates $\left(F_{1,26}=69.44, P<\right.$ 0.0001 ; Fig. 4A). There was also higher recruitment to vials with amino acids $\left(F_{1,26}=4.08, P=0.05\right)$; however, the effect of amino acids on recruitment ( $35 \%$ increase) was much smaller than the effect of carbohydrates (264\% increase; Fig. 4A). There was no interaction between carbohydrates and amino acids $\left(F_{1,26}=0.39, P\right.$ $=0.54)$.

\section{Diet choice in the field}

In a simultaneous choice experiment in the field, $S$. invicta recruited to baits with carbohydrates in much higher numbers than they did to vials with no carbohydrates $\left(F_{1,87}=103.54, P<0.0001\right.$; Fig. 4 B $)$. In parallel with the results in the laboratory, S. invicta recruited to vials with amino acids in higher numbers than they did to vials without amino acids $\left(F_{1,87}=4.29\right.$, $P=0.04$ ), but the effect for amino acids ( $36 \%$ increase in recruitment) was much smaller than the effect for carbohydrates $(651 \%$ increase in recruitment; Fig. 4B). There was no interaction between carbohydrates and amino acids in the recruitment of ants to baits $\left(F_{1,87}=\right.$ $0.04, P=0.84)$.

\section{Discussion}

By decoupling the separate effects of the carbohydrate and amino acid components of extrafloral nectar, our data show that, even when provided with ad libitum insect prey, carbohydrates limited S. invicta colony growth. Colonies that had their diet of insect prey supplemented with carbohydrate-only supplements (experiment 2) and honeydew (experiment 1) had similar increases in worker and brood mass. Amino acid supplements had no effect on colony growth and a negative effect on worker survival. The only potential positive effect of amino acids was that colonies provided with the supplement containing a combination of carbohydrates and amino acids had a slight increase in the ratio of brood to workers compared to colonies with only the carbohydrate supplement. The strong dietary preferences of $S$. invicta for carbohydrate supplements in the field matched their performance on those supplements in the laboratory. Many species of predatory arthropods consume plant-based resources in nature and show higher fitness when consuming these resources (Wäckers et al. 2005). However, this is the first study to decouple the nutritional components of plant-based resources and demonstrate that carbohydrates, and not amino acids, contribute to increased production of both brood and workers of a primarily carnivorous ant.

The amino acids in plant-based foods have been hypothesized to be an important resource for arthropod mutualists and many arthropods prefer plant-based foods that contain higher concentrations of amino acids (Lanza 1991, Yanoviak and Kaspari 2000, Blüthgen and Fiedler 2004, Davidson 2005). Solenopsis invicta also shows a slight preference for amino acids. When amino acids are consumed alone this does not seem to be beneficial because it increases worker mortality without any benefit to colony growth. In this case, the small consumption of amino acids may represent some ants sampling the resource or over-ingesting the overall

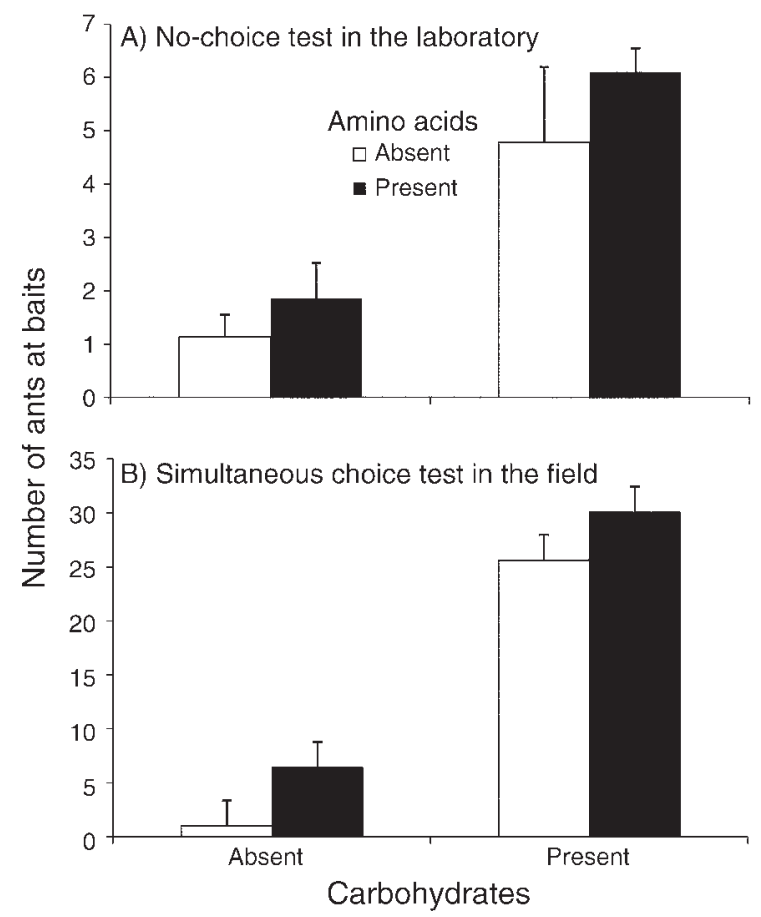

FIG. 4. Comparisons of the effects of a full factorial manipulation of the presence and absence of the carbohydrate and amino acids components of artificial extrafloral nectar on the recruitment of Solenopsis invicta workers to baits (mean + $\mathrm{SE})$ : the recruitment of workers to baits (A) in the laboratory when they were only provided with one type of bait and (B) in the field when they were provided with all four bait types simultaneously. 
amino acid solution to gain limiting dietary essential amino acids (e.g., five of the amino acids in our solution are considered dietary essential for insects; Chapman 1998). However, colonies do gain a slight benefit in the proportion of a colony composed of brood when the amino acids are combined with carbohydrates. The fact that the effect of amino acids is small may not be surprising given that carnivorous $S$. invicta primarily consume insects, which are rich in amino acids (e.g., $>60 \%$ amino acids by dry mass; Ramos-Elorduy et al. $1997)$ compared to plant-based foods $(<1 \%$ amino acid by dry mass; Blüthgen et al. 2004). Clearly, S. invicta show a much higher preference and increase in colony growth with carbohydrates than amino acids, and this preference may have been a strong selective factor influencing the nutritional composition of plant-based foods, which typically have a lower concentration of amino acids and higher concentration of carbohydrates than phloem sap (Byrne and Miller 1990, Blüthgen et al. 2004, Hu et al. 2009).

Extrafloral nectar and honeydew both contain amino acids, which are thought to be costly to incorporate into these plant-based resources (Bronstein 1998). However, our data suggest that these amino acids may only have a slight benefit on colony growth of S. invicta, which questions why they are incorporated into plant-based foods. One hypothesis is that the amino acids in plantbased foods are important when insect prey are limited or for species that feed less on insect prey (e.g., more "herbivorous" ant species; Davidson et al. 2003). Amino acids could also act as phagostimulants and be added in extrafloral nectar by plants to distract ants from tending hemipterans (Hanny and Elmore 1974, Becerra and Venable 1989). Yet another hypothesis is that these amino acids are not as costly as once thought. Plants and some hemipterans have mutualist microbes that synthesize amino acids and there could be times when excess amino acids are produced and need to be voided (Fischer et al. 1998, Douglas 2006). For example, aphids require certain essential amino acids in their diet, which are often limited, and will void excess nonessential amino acids in honeydew (Douglas 1993, Sandström and Moran 2001, Douglas 2006). Hence, amino acids need not be an addition designed to benefit mutualist consumers but, rather, could be an excess product of another mutualism between the plant or hemipteran and their symbiotic microbes (Fischer et al. 1998, Douglas 2006).

Carnivorous arthropods have long been hypothesized to be nitrogen limited (White 1978, Fagan et al. 2002, Denno and Fagan 2003, Fagan and Denno 2004). However, recent empirical data do not support this hypothesis and, instead, suggest that some carnivorous arthropods may be energy limited (e.g., Raubenheimer et al. 2007, Salomon et al. 2008). Our results and those of several recent studies have shown that some carnivorous arthropods preferentially forage for energetic compounds (i.e., carbohydrates and lipids) and that feeding on diets high in energetic compounds contributes to increased mass gain, growth, and reproduction (Raubenheimer et al. 2007, Dussutour and Simpson 2008, 2009, Salomon et al. 2008, Cook et al. 2010, Kay et al. 2010). A more critical analysis of the nitrogen limitation hypothesis reveals that several key assumptions of this hypothesis may not be met, which may explain why it is not supported by experimental data (Wilder and Eubanks 2010). While the nitrogen limitation hypothesis assumes that the dietary requirements of arthropods are directly proportional to the nutrients in their bodies, the actual dietary requirements of arthropods can be inversely related to their body contents (Fagan et al. 2002, Wilder and Eubanks 2010). For example, in the spring, Agonum dorsale beetles have high protein and low lipid contents in their bodies but preferentially forage for lipid in their diet to restore lipid reserves that were depleted during diapause (Raubenheimer et al. 2007). The controversy over nutrient limitation in carnivorous arthropods highlights the need for direct experimental data to critically evaluate longstanding hypotheses that have yet to be rigorously tested.

The digestive physiology of larval and adult ants may contribute to the large effect of carbohydrates on colony growth. Most insects can metabolize carbohydrates, lipids, and amino acids to acquire energy (Paine 1971, Wigglesworth 1984). However, in ants and some other social insects, castes differ in their digestive abilities (Tschinkel 2006). While larvae can process a wide range of food typical of the capabilities exhibited by most solitary insects, adult worker ants have a reduced digestive system that cannot process insect prey and, instead, rely on carbohydrates for fuel (Vinson 1983, Tschinkel 2006). All insect prey items are brought by workers to the larvae, processed and digested by the larvae, and then redistributed throughout the colony (i.e., to the queen, workers, and other larvae) as needed through trophallaxis (Vinson 1983, Tschinkel 2006). Hence, consumption of carbohydrates has a double benefit to colony growth of ants by directly providing energy to fuel worker foraging and by allowing larvae to divert more resources to their own growth and less toward processing food for workers. The dual benefit of carbohydrates may explain the large effect that carbohydrates had on colony growth of $S$. invicta and why mutualisms between ants and honeydew-producing insects or plants with extrafloral nectaries are extremely common in nature (Hölldobler and Wilson 1990, Helms and Vinson 2002, Stadler and Dixon 2005). In addition, access to plant-based carbohydrates in its introduced range could play an important role in the invasion ecology of S. invicta.

Research on nutritional ecology and ecological stoichiometry has provided tremendous insight into ecology and evolution at scales ranging from chemical reactions to ecosystem dynamics (Sterner and Elser 2002, Simpson et al. 2009). However, relatively few 
studies have been conducted on the nutritional ecology of carnivores (Raubenheimer et al. 2007) despite the importance of carnivore nutrition for the ecological impacts of predators in biological control and as invasive species (e.g., Kaplan and Eubanks 2005). Our results contribute to the growing evidence that sources of energy (e.g., carbohydrates and lipid; Raubenheimer et al. 2007, Salomon et al. 2008) can limit the growth of carnivorous arthropods despite long-held beliefs that nutrients (e.g., nitrogen and phosphorus) limit the growth of predators and a range of other animals (White 1978, Fagan et al. 2002, Sterner and Elser 2002). The strong benefit of carbohydrates for carnivorous ants and the low cost of including carbohydrates in plantbased foods by plants and hemipterans may have aided the evolution of food-for-protection mutualisms and help explain why these mutualisms are so common (O'Dowd 1979, Stadler and Dixon 2005, Wäckers et al. 2005). Further research on the nutritional ecology of carnivores will aid in developing integrated models of nutrition to explain how small-scale processes such as individual foraging behavior scale to community and ecosystem dynamics (Simpson et al. 2009).

\section{ACKNOWLEDGMENTS}

We thank Kenneth Helms for comments on a previous version of the manuscript. Michael Castro and Hannah McKenrick provided valuable help with laboratory and field experiments. Funding was provided by NSF DEB 0716983 to M. D. Eubanks, NSF DEB 0717054 to D. A. Herre, and NSF DEB 0716966 to A. V. Suarez.

\section{Literature Cited}

Adjei-Maafo, I. K., and L. T. Wilson. 1983. Association of cotton nectar production with Heliothis punctigera (Lepidoptera: Noctuidae) oviposition. Environmental Entomology 12:1166-1170.

Becerra, J. X. I., and D. L. Venable. 1989. Extrafloral nectaries: A defense against ant-Homoptera mutualisms? Oikos 55: 276-280.

Blüthgen, N., and K. Fiedler. 2004. Preferences for sugars and amino acids and their conditionality in a diverse nectarfeeding ant community. Journal of Animal Ecology 73:155166.

Blüthgen, N., G. Gottsberger, and K. Fiedler. 2004. Sugar and amino acid composition of ant-attended nectar and honeydew sources from an Australian rainforest. Austral Ecology 29:418-429.

Bronstein, J. L. 1994. Our current understanding of mutualism. Quarterly Review of Biology 69:31-51.

Bronstein, J. L. 1998. The contribution of ant-plant protection studies to our understanding of mutualism. Biotropica 30: $150-161$.

Byrne, D. N., and W. B. Miller. 1990. Carbohydrate and amino acid composition of phloem sap and honeydew produced by Bemisia tabaci. Journal of Insect Physiology 36:433-439.

Chapman, R. F. 1998. The insects: structure and function. Cambridge University Press, New York, New York, USA.

Cook, S. C., M. D. Eubanks, R. E. Gold, and S. T. Behmer. 2010. Colony-level macronutrient regulation in ants: mechanisms, hoarding and associated costs. Animal Behaviour 79: 429-437.

Davidson, D. W. 2005. Ecological stoichiometry of ants in a New World rain forest. Oecologia 142:221-231.
Davidson, D. W., S. C. Cook, R. R. Snelling, and T. H. Chua. 2003. Explaining the abundance of ants in lowland tropical rainforest canopies. Science 300:969-972.

Denno, R. F., and W. F. Fagan. 2003. Might nitrogen limitation promote omnivory among carnivorous arthropods? Ecology 84:2522-2531.

Douglas, A. E. 1993. The nutritional quality of phloem sap utilized by natural aphid populations. Ecological Entomology 18:31-38.

Douglas, A. E. 2006. Phloem-sap feeding by animals: problems and solutions. Journal of Experimental Botany 57:747-754.

Dussutour, A., and S. J. Simpson. 2008. Carbohydrate regulation in relation to colony growth in ants. Journal of Experimental Biology 211:2224-2232.

Dussutour, A., and S. J. Simpson. 2009. Communal nutrition in ants. Current Biology 19:1-5.

Eubanks, M. D. 2005. Predaceous herbivores and herbivorous predators: the biology of omnivores and the ecology of omnivore-prey interactions. Pages 3-16 in P. Barbosa and I. Castellanos, editors. The ecology of predator-prey interactions. Oxford University Press, New York, New York, USA.

Fagan, W. F., and R. F. Denno. 2004. Stoichiometry of actual vs. potential predator-prey interactions: insights into nitrogen limitation for arthropod predators. Ecology Letters 7: 876-883.

Fagan, W. F., E. Siemann, C. Mitter, R. F. Denno, A. F. Huberty, H. A. Woods, and J. J. Elser. 2002. Nitrogen in insects: implications for trophic complexity and species diversification. American Naturalist 160:784-802.

Fischer, M. K., W. Völkl, R. Schopf, and K. H. Hoffmann. 2002. Age-specific patterns in honeydew production and honeydew composition in the aphid Metopeurum fuscoviride: implications for ant-attendance. Journal of Insect Physiology 48:319-326.

Fischer, W. N., B. André, D. Rentsch, S. Krolkiewicz, M. Tegeder, K. Breitkreuz, and W. B. Frommer. 1998. Amino acid transport in plants. Trends in Plant Science 3:13601385.

Gayahan, G. G., and W. R. Tschinkel. 2008. Fire ants, Solenopsis invicta, dry and store insect pieces for later use. Journal of Insect Science 8:1-8.

González-Teuber, M., and M. Heil. 2009. Nectar chemistry is tailored for both attraction of mutualists and protection from exploiters. Plant Signaling and Behavior 4:809-813.

Hainsworth, F. R., and L. L. Wolf. 1972. Energetics of nectar extraction in a small, high altitude, tropical hummingbird, Selasphorus flammula. Journal of Comparative Physiology A 80:377-387.

Hanny, B. W., and C. D. Elmore. 1974. Amino acid composition of cotton nectar. Journal of Agricultural and Food Chemistry 22:476-478.

Helms, K. R., and S. B. Vinson. 2002. Widespread association of the invasive ant Solenopsis invicta with an invasive mealybug. Ecology 83:2425-2438.

Helms, K. R., and S. B. Vinson. 2008. Plant resources and colony growth in an invasive ant: the importance of honeydew-producing hemiptera in carbohydrate transfer across trophic levels. Environmental Entomology 37:487493.

Hölldobler, B., and E. O. Wilson. 1990. The ants. Harvard University Press, Cambridge, Massachusetts, USA.

Hu, L. P., F. Z. Meng, S. H. Wang, X. L. Sui, W. Li, Y. X. Wei, J. L. Sun, and Z. X. Zhang. 2009. Changes in carbohydrate levels and their metabolic enzymes in leaves, phloem sap and mesocarp during cucumber (Cucumis sativus L.) fruit development. Sciencia Horticulturae 121:131-137.

Josens, R. B., and W. M. Farina. 1997. Selective choice of sucrose concentration by the hovering hawk moth Macroglossum stellatarum. Journal of Insect Behavior 10:631-637.

Kaplan, I., and M. D. Eubanks. 2005. Aphids alter the community-wide impact of fire ants. Ecology 86:1640-1649. 
Kay, A. D., T. Zumbusch, J. L. Heinen, T. C. Marsh, and D. A Holway. 2010. Nutrition and interference competition have interactive effects on the behavior and performance of Argentine ants. Ecology 91:57-64.

Lanza, J. 1991. Response of fire ants (Formicidae: Solenopsis invicta and $S$. geminata) to artificial nectars with amino acids. Ecological Entomology 16:203-210.

Mayntz, D., D. Raubenheimer, M. Salomon, S. Toft, and S. J. Simpson. 2005. Nutrient-specific foraging in invertebrate predators. Science 307:111-113.

Mayntz, D., and S. Toft. 2001. Nutrient composition of the prey's diet affects growth and survivorship of a generalist predator. Oecologia 127:207-213.

O'Dowd, D. 1979. Foliar nectar production and ant activity on a neotropical tree, Ochroma pyramidale. Oecologia 43:185191.

Paine, R. T. 1971. The measurement and application of the calorie to ecological problems. Annual Review of Ecology and Systematics 2:145-164.

Ramos-Elorduy, J., J. M. P. Moreno, E. E. Prado, M. A. Perez, J. L. Otero, and O. L. de Guevara. 1997. Nutritional value of edible insects from the state of Oxaca, Mexico. Journal of Food Composition and Analysis 10:142-157.

Raubenheimer, D., D. Mayntz, S. J. Simpson, and S. Toft. 2007. Nutrient-specific compensation following diapauses in a predator: implications for intraguild predation. Ecology 88: 2598-2608.

Salomon, M., D. Mayntz, and Y. Lubin. 2008. Colony nutrition skews reproduction in a social spider. Behavioral Ecology 19:605-611.

Sandström, J. P., and N. A. Moran. 2001. Amino acid budgets in three aphid species using the same host plant. Physiological Entomology 26:202-211.

Simpson, S. J., D. Raubenheimer, M. A. Charleston, F. J. Clissold, and the ARC-NZ Vegetation Function Network Herbivory Working Group. 2009. Modelling nutritional interactions: from individuals to communities. Trends in Ecology and Evolution 25:53-60.
Stadler, B., and A. F. G. Dixon. 2005. Ecology and evolution of aphid-ant-interactions. Annual Review of Ecology, Evolution, and Systematics 36:345-372.

Sterner, R. W., and J. J. Elser. 2002. Ecological stoichiometry: the biology of elements from molecules to the biosphere. Princeton University Press, Princeton, New Jersey, USA.

Tennant, L. E., and S. D. Porter. 1991. Comparison of the diets of two fire ant species (Hymenoptera: Formicidae): solid and liquid components. Journal of Entomological Science 26: 450-465.

Tillberg, C. V., D. A. Holway, E. G. LeBrun, and A. V. Suarez. 2007. Trophic ecology of invasive Argentine ants in their native and introduced ranges. Proceedings of the National Academy of Sciences USA 104:20856-20861.

Tschinkel, W. R. 2006. The fire ants. Belknap Press, Cambridge, Massachusetts, USA.

Vinson, S. B. 1983. The physiology of the imported fire ant revisited. Florida Entomologist 66:126-139.

Vogt, J. T., R. A. Grantham, E. Corbett, S. A. Rice, and R. E. Wright. 2002. Dietary habits of Solenopsis invicta (Hymenoptera: Formicidae) in four Oklahoma habitats. Environmental Entomology 31:47-53.

Wäckers, F. L., P. C. J. van Rijn, and J. Bruin. 2005. Plant provided food for carnivorous insects: a protective mutualism and its applications. Cambridge University Press, Cambridge, UK.

White, T. C. R. 1978. The importance of a relative shortage of food in animal ecology. Oecologia 33:71-86.

Wigglesworth, V. B. 1984. Insect physiology. University Press, Cambridge, UK.

Wilder, S. M., and M. D. Eubanks. 2010. Might nitrogen limitation promote omnivory among carnivorous arthropods? Comment. Ecology 91:3114-3117.

Yanoviak, S. P., and M. Kaspari. 2000. Community structure and the habitat templet: ants in the tropical forest canopy and litter. Oikos 89:259-266. 